\title{
An ecological framework for the development of a national MPA network
}

\author{
David Abecasis $^{1, *}$, Pedro Afonso ${ }^{2,3}$ and Karim Erzini ${ }^{1}$ \\ ${ }^{1}$ Centre of Marine Sciences (CCMAR), University of the Algarve, Campus de Gambelas, 8005-139 Faro, Portugal \\ ${ }^{2}$ Institute of Marine Research (IMAR), Department of Oceanography and Fisheries, University of the Azores, 9901-862 Horta, Portugal \\ ${ }^{3}$ Marine and Environmental Sciences Centre (MARE), Universidade dos Açores, 9901-862 Horta, Portugal
}

Received 14 October 2016 / Accepted 9 March 2017

\begin{abstract}
Isolated marine protected areas (MPAs) may not be enough to sustain viable populations of marine species, particularly the many small coastal MPAs which resulted due to social, economic and political constraints. Properly designed MPA networks can circumvent such limitations due to their potential synergistic positive effects, but this crucial step is frequently obstructed by lack of baseline ecological information. In this paper, we use systematic conservation planning on European Nature Information System coastal habitat information available for Portugal to demonstrate how an ecologically coherent nation-wide MPA network can be designed. We used the software Marxan to obtain near optimal solutions for each of three pre-determined conservation targets $(10 \%, 30 \%$ and $50 \%$ protection) while maintaining the cost of including conservation units as low as possible. Marxan solutions were subsequently optimized with MinPatch by keeping each MPA above a minimum size that reflects the existing information on habitat use by some key marine fishes. Results show that $10 \%$ protection for all habitats would only require a relativelly small increase in the number (from 6 to 10) and area (from $479 \mathrm{~km}^{2}$ to $509 \mathrm{~km}^{2}$ ) of already existing MPAs in mainland Portugal whereas substantial increases would be required to achieve the $50 \%$ target. This rather simple approach offers the added benefit of allowing design improvement as more relevant ecological information becomes available, including deeper habitat mapping across the whole continental shelf, allowing a coherent, adaptive and inclusive optimal MPA network to be designed.
\end{abstract}

Keywords: Marxan / MinPatch / EUNIS / Marine protected areas

\section{Introduction}

Over the last decades it became common knowledge that human impacts can cause the drastic degradation of marine ecosystems and that these impacts have been increasing in magnitude, diversity and rates of change (Jackson et al., 2001). Worldwide, scientists have documented the devastating effects of overexploitation (Pauly et al., 2005), habitat loss (Short and Wyllie-Echeverria, 1996; Gray, 1997), pollution (Jackson et al., 2001; Shahidul Islam and Tanaka, 2004), invasive species (Molnar et al., 2008) and the negative consequences of increasing coastal development (Bulleri and Chapman, 2010) and tourism (Hall, 2001). These factors have raised serious concerns and led to calls for the implementation of measures that aim to protect, preserve and restore marine ecosystems (Lubchenco et al., 2003).

One measure that has received much attention and support from the scientific community over the last 30 years is the

\footnotetext{
* Corresponding author: davidbecas@gmail.com
}

implementation of marine protected areas (MPAs) (Roberts and Polunin, 1991; Guénette et al., 1998; Kaiser, 2011). Although not a new approach to conservation, MPA research and implementation have escalated since the 1990s (Roberts and Polunin, 1991; Agardy et al., 2003; McCay and Jones, 2011). During the 2010 Conference on Biological Diversity a series of targets (known as Aichi targets) were established, including a $10 \%$ protection target for marine and coastal areas to be achieved by 2020 (https://www.cbd.int/sp/targets/). More recently, during the 2014 World Parks Congress, a recommendation was made for $30 \%$ protection for each marine habitat (http://worldparkscongress.org/about/promise_of_syd ney.html). A recent study has shown that these protection targets $(10-30 \%)$ are compatible with both biodiversity conservation and fisheries management objectives (Krueck et al., 2017).

MPAs have been strongly recommended as a complement to traditional fisheries management methods (Murawski et al., 2000; Pauly et al., 2005; Kaiser, 2011), given that spatial protection can enhance fish abundance and biomass inside 
(Abecasis et al., 2015a and references therein) but also outside MPAs through the spillover of eggs, larvae and adults, potentially increasing fisheries catches (Di Lorenzo et al., 2016 and references therein). MPAs focusing on biodiversity and habitat conservation include an array of specific objectives such as protecting rare and vulnerable habitats and species, restoring ecological functions, encouraging research and education, maintaining aesthetic values and traditional uses and promoting sustainable tourism and the area's nonconsumptive values (Jones, 2001).

Recent studies have shown that single coastal MPAs can play an important role in protecting local adult (sub) populations of some coastal fish species (Abecasis et al., 2015a; Afonso et al., 2016). Yet, in most cases these single MPAs cannot assure (1) the genetic diversity of viable populations, (2) the protection of migratory, wider ranging individuals, neither (3) the protection of multiple essential fish habitats (nursery, reproduction, adult habitats) and connections between them (Agardy et al., 2011). These caveats mainly result from the fact that coastal MPAs are typically quite small in size and isolated, as they were not designed to form ecologically coherent and connected networks. Therefore, their contribution to broader-scale conservation objectives can be very limited. However, properly designed MPA networks can ensure the adequacy, connectivity, protection, replication, representation and viability of this conservation tool (Metcalfe et al., 2015) and thus effectively contribute to conservation (Gaines et al., 2010).

Policy makers increasingly recognize this potential and the European Union (EU) Marine Strategy Framework Directive (MSFD, 2008/56/EC) now mandates member states to implement coherent MPA networks to achieve Good Environmental Status by 2020.

Properly designed MPA networks can circumvent limitations of isolated MPAs due to their potential synergistic positive effects, but this crucial step is frequently obstructed by lack of baseline ecological information. Several studies have focused on the different types of information (e.g. connectivity, habitat type, species distributions) needed to support adequate MPA network designs (e.g. Ban et al., 2009; Jones and Carpenter, 2009; Smith et al., 2009; Magris et al., 2014) and recognize that, in most cases, only a small part of this information is available. Only data on habitat type is available across EU coastal waters even if other datasets exist at the regional or national levels (e.g. Jones and Carpenter, 2009; Di Franco et al., 2012; Horta e Costa et al., 2013).

In this study we use the information on benthic habitat classification available at the European Marine Observation and Data Network (www.emodnet.eu) as a surrogate for marine biodiversity and the baseline upon which to design an ecologically coherent MPA network for the coastal waters of Portugal. This is a maritime country with considerable coastline and a very diverse array of marine habitats due to its ecotone biogeographic position, thus constituting an excellent case study. We focused on coastal areas profiting from current availability of habitat maps for these areas but also because, as in most other maritime countries, they withstand the highest and most diverse human impacts and are thus of priority for marine conservation. This work constitutes the first step of a progressively incremented process towards a nation-wide MPA network design.

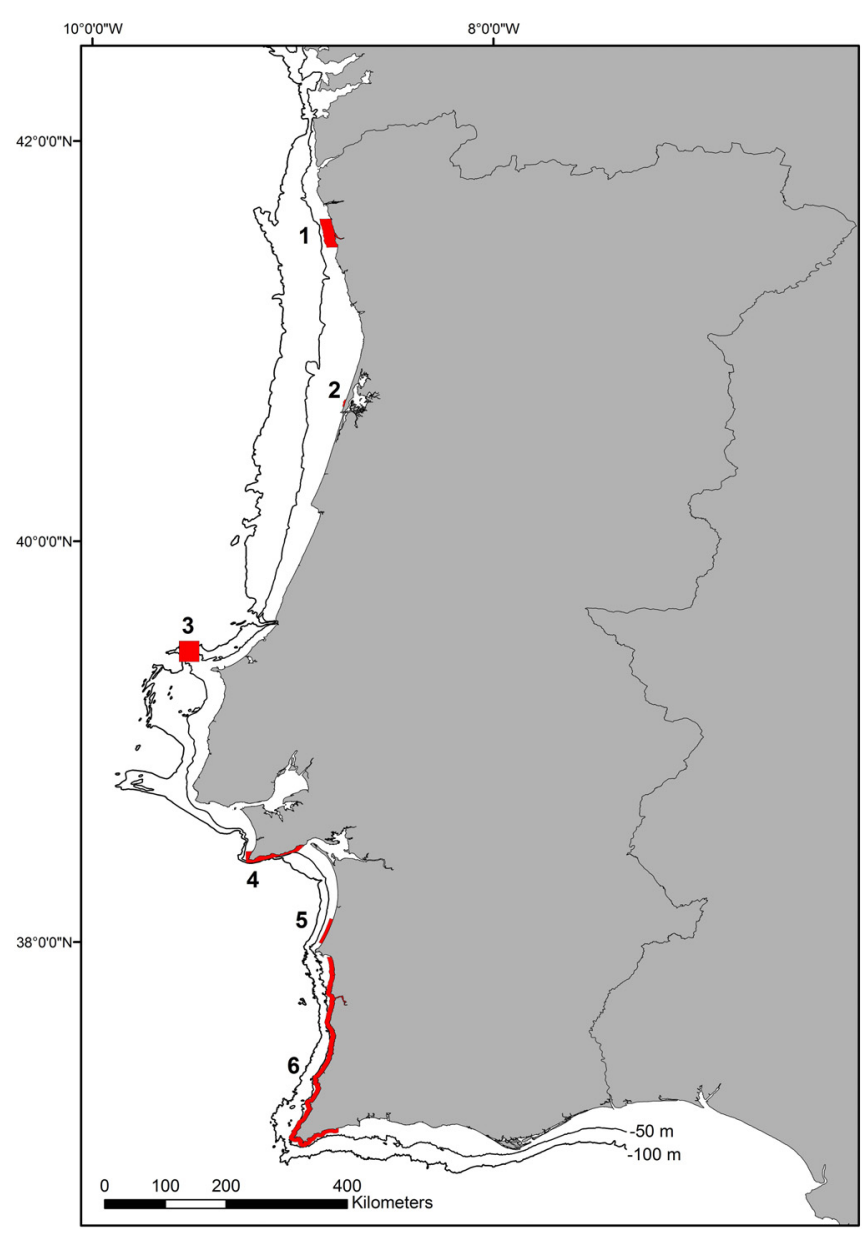

Fig. 1. Map of the study area showing the six existing MPAs (in red: 1-Litoral Norte, 2-Reserva Natural Duna São Jacinto, 3- Reserva Natural Lagoa Sto André, 4-Berlengas, 5- Arrábida, 6-Parque Natural Sudoeste Alentejano e Costa Vicentina) and the 50 and $100 \mathrm{~m}$ depth contours.

\section{Materials and methods}

We used the coastal component of mainland Portugal's Exclusive Economic Zone (EEZ) as our study area, defined as the area between the coastline down to the $100 \mathrm{~m}$ deep contour. The Portuguese coastline is approximately $943 \mathrm{~km}$ long and contains a variety of habitats including large estuaries and coastal lagoons, rocky shores and mobile substrates (Fig. 1). There are six MPAs in the study area (Table 1). Together, they cover $479 \mathrm{~km}^{2}$ and represent $3.6 \%$ of the total study area, which is less than $0.0015 \%$ of the total Portuguese EEZ and $0.03 \%$ of the Portuguese territorial waters. Moreover, the total no-take area within these six MPAs combined covers a mere $5 \mathrm{~km}^{2}$, approximately $0.0003 \%$ of the territorial waters. These MPAs are on average $61.2 \mathrm{~km}^{2}$ in size (ranging from $2.2 \mathrm{~km}^{2}$ to $253.4 \mathrm{~km}^{2}$ ) and separate from each other an average distance of $80 \mathrm{~km}$.

The recently established European Marine Observation and Data Network is a long-term marine data initiative from the European Commission supporting the Marine 2020 strategy. Its main objective is to gather marine data resources and make them available to public and private stakeholders. 
Table 1. Current marine protected areas implemented in mainland Portugal and some of their characteristics.

\begin{tabular}{lcl}
\hline Designation & $\begin{array}{l}\text { Total size } \\
\left(\mathrm{km}^{2}\right)\end{array}$ & $\begin{array}{l}\text { No-take } \\
\text { area }\left(\mathrm{km}^{2}\right)\end{array}$ \\
\hline Litoral Norte & 69.94 & - \\
Reserva Natural Duna São Jacinto & 2.21 & - \\
Reserva Natural Lagoa Sto André & 21.93 & - \\
Berlengas & 79.25 & - \\
Arrábida & 52.37 & 4.32 \\
Parque Natural Sudoeste Alentejano & 253.37 & 0.63 \\
e Costa Vicentina & & \\
& & \\
Total & 479.07 & 4.95 \\
\hline
\end{tabular}

-, absence of no-take areas.

This database is expected to comprise data on: bathymetry, geology, physics, chemistry, biology, seabed habitats and human activities (www.emodnet.eu). Data on habitat classification was based on the European Nature Information System (EUNIS) and obtained from the European Marine Observation and Data Network (http://www.emodnet-seabedhabitats.eu/). Twenty-eight different marine habitats were identified in the study area. Additionally, we also included vulnerable marine ecosystems (VMEs) listed under the OSPAR convention available in the literature such as red corals (Boavida et al., 2016), seagrass beds (Cunha et al., 2013) and Maerl beds (Peña et al., 2014).

Marxan (Ball et al., 2009), a systematic conservation planning software, was used to obtain near-optimal solutions for three different conservation scenarios for which goals were set based on literature review (Murawski et al., 2000; Airame et al., 2003; Fraschetti et al., 2009; Krueck et al., 2017). In the first scenario, the objective was to protect at least $10 \%$ of each existing habitat (the 28 EUNIS plus the three VMEs), the goal of the second scenario was to protect at least $30 \%$ of each habitat, and for the third scenario the goal was to obtain at least $50 \%$ of protection for each habitat. We divided the study area in 28741 hexagonal planning units of $0.5 \mathrm{~km}^{2}$ and ran 100 models with $1 \times 10^{9}$ iterations for each scenario. The existing MPAs were kept as fixed conditions and always kept in the final solutions. Marxan models were fine tuned to achieve compact solutions using the boundary length modifier (BLM).

These models were then modified using MinPatch (Smith et al., 2010), a software that modifies the outputs from Marxan to ensure that each protected area is larger than a specified minimum size threshold. This step is essential to avoid solutions with excessive fragmentation and inefficient areas of very small size. Although most conservation planning software, including Marxan, include an option to reduce the fragmentation of the protected areas, this procedure is insufficient because it increases the size of all protected areas. To determine an ecologically meaningful minimum size threshold, we used the results of our previous acoustic telemetry studies on the dynamic habitat use of some fish species, including key ecological and commercial species (Sparus aurata, Abecasis and Erzini, 2008; Sarpa salpa, Abecasis et al., 2012; Solea senegalensis, Abecasis et al., 2014; Diplodus sargus, Abecasis et al., 2015b;
Table 2. Summary of the Marxan and MinPatch runs for the three conservation scenarios. Average distance represents the average of the distances between two neighboring MPAs. It was not estimated for the Marxan solutions given the high number of MPAs and small distances between them.

\begin{tabular}{|c|c|c|c|}
\hline $\begin{array}{l}\text { Conservation } \\
\text { scenario }\end{array}$ & Characteristic & Marxan & MinPatch \\
\hline \multirow{5}{*}{$10 \%$ protection } & Number of MPAs & 105 & 11 \\
\hline & Number of MPAs $>5 \mathrm{~km}^{2}$ & 5 & 10 \\
\hline & Total area MPAs & $495 \mathrm{~km}^{2}$ & $509 \mathrm{~km}^{2}$ \\
\hline & MPA size (median) & $0.06 \mathrm{~km}^{2}$ & $7.63 \mathrm{~km}^{2}$ \\
\hline & Average MPA-MPA distance & - & $52 \mathrm{~km}$ \\
\hline \multirow{5}{*}{$30 \%$ protection } & Number of MPAs & 424 & 26 \\
\hline & Number of MPAs $>5 \mathrm{~km}^{2}$ & 10 & 26 \\
\hline & Total area MPAs & $822 \mathrm{~km}^{2}$ & $821 \mathrm{~km}^{2}$ \\
\hline & MPA size (median) & $0.05 \mathrm{~km}^{2}$ & $11.13 \mathrm{~km}^{2}$ \\
\hline & Average MPA-MPA distance & - & $17.5 \mathrm{~km}$ \\
\hline \multirow{5}{*}{$50 \%$ protection } & Number of protected areas & 311 & 27 \\
\hline & Protected areas $>5 \mathrm{~km}^{2}$ & 44 & 27 \\
\hline & Total area MPAs & $1215 \mathrm{~km}^{2}$ & $1217 \mathrm{~km}^{2}$ \\
\hline & MPA size (median) & $0.91 \mathrm{~km}^{2}$ & $21.98 \mathrm{~km}^{2}$ \\
\hline & Average MPA-MPA distance & - & $11.8 \mathrm{~km}$ \\
\hline
\end{tabular}

Epinephelus marginatus and Serranus atricauda, Afonso et al., 2016). Using the estimated home range obtained in these studies we established a minimum no-take area size of $5 \mathrm{~km}^{2}$. The average size and distance between protected areas was then estimated for each MinPatch solution.

\section{Results}

The models obtained by Marxan for the three scenarios predict a much higher number of protected areas when compared with the optimized solutions provided by MinPatch (Table 2 and Fig. 2). Yet, the total area enclosed by protection is very similar in both the Marxan and MinPatch solutions. All MinPatch optimized solutions including the $10 \%$ scenario predict protected areas above the minimum size threshold (Table 2), except for the already existing Reserva Natural Duna São Jacinto $\left(2.2 \mathrm{~km}^{2}\right.$, Table 1). The more evident difference between the Marxan and MinPatch results was the average size of protected areas: for the $10 \%$ and $30 \%$ scenarios the median size of the resulting Marxan protected areas was similar to the size of the planning units whereas those of MinPatch were substantially larger $\left(0.06 \mathrm{vs} .7 .6 \mathrm{~km}^{2}\right.$ and $0.05 \mathrm{vs}$. $22 \mathrm{~km}^{2}$, respectively) (Table 2). The average distance between MPAs was smaller in the MinPatch solutions (52-11.8 km) than the average $80 \mathrm{~km}$ between existing MPAs.

\section{Discussion}

The use of systematic conservation planning is considered the most efficient method to achieve the optimal design of 
Marxan solutions

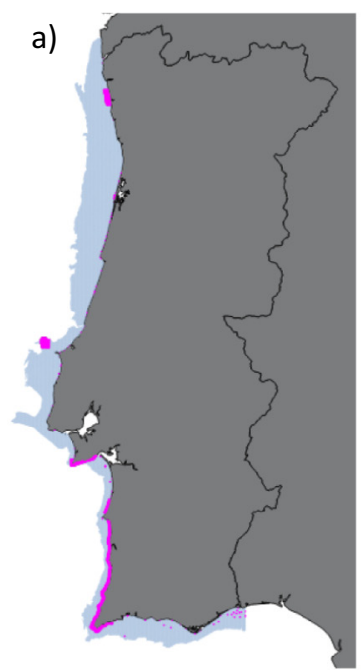

c)

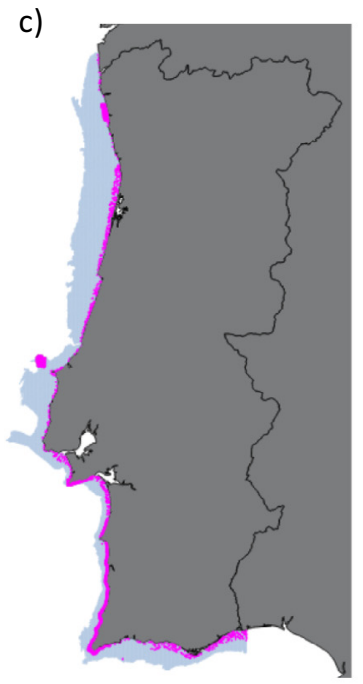

e)

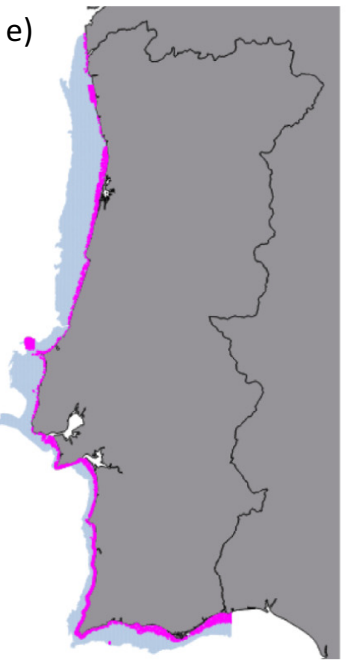

MinPatch solutions

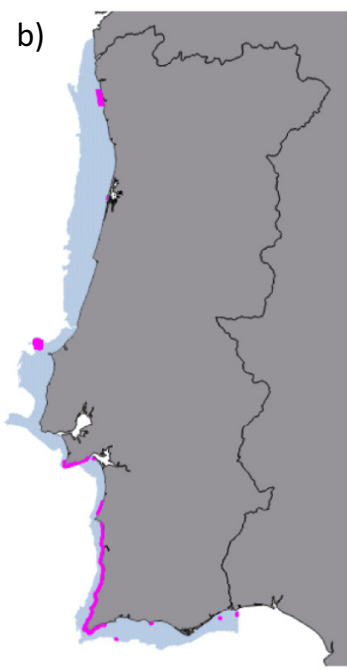

d)
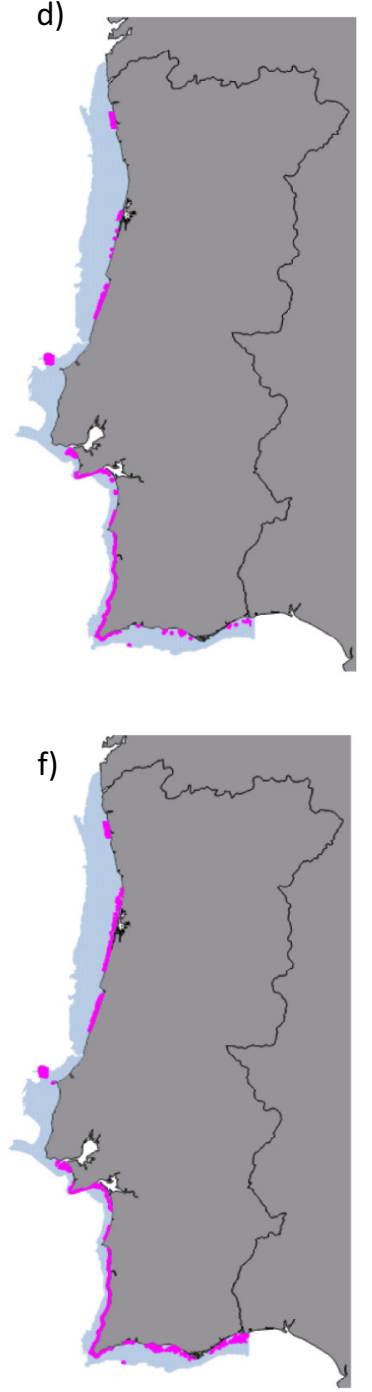

Fig. 2. Results of the solutions provided by Marxan (a, c, e) and MinPatch solutions (b, d, f) for the $10 \%, 30 \%$ and $50 \%$ conservation scenarios. Protected areas are shown in pink.

protected area networks (Margules and Pressey, 2000; Smith et al., 2010), and Marxan is one of the most widely used software for this purpose (Ball et al., 2009). This is the first effort to do so for the marine coastal habitats of mainland Portugal as a whole. As preliminary as it may be within an adaptive process, our results already demonstrate that a coherent network design is possible in relatively data poor situations, while clearly revealing the need for substantial improvement in the existing assemblage of MPAs if the country is to achieve the national and international goals and commitments in marine conservation. In agreement with previous report by Smith et al. (2010) our results also show that MinPatch greatly improves the solutions provided by Marxan by achieving the same amount of protection with less protected areas while ensuring their minimum ecological significance. As in any modeling, several aspects and technicalities need to be understood and addressed if one is to use it in support of marine conservation.

First, to obtain the best potential network design in terms of MPA efficiency one should take in consideration information on a variety of ecological, biological and social aspects (Smith et al., 2009). The results of our study rely on benthic habitat classification mapping since it was the main available information at the national and regional levels, and it is a proven proxy for biodiversity (Smith et al., 2009). For example, Portugal's coastal habitats are essentially targeted by small-scale artisanal and recreational fisheries but information on this fishing effort is still scarce, dispersed and not publicly available (Veiga et al., 2010; Horta e Costa et al., 2013) and therefore could not be used. Moreover, the results provided by systematic conservation planning software should be regarded as a starting point rather than a compulsory final design. The continuous improvement of the conservation planning solutions through the inclusion of new data as it becomes available is a working process that provides an objective presentation of the best available knowledge to stakeholders and support discussions during the multiple steps of MPA network design and evaluation (Smith et al., 2009; Mills et al., 2015).

Second, choosing the conservation targets obviously has a large influence on the final solutions. Some authors suggest that no-take areas may not be effective as a primary management tool unless more than $20 \%$ is closed (e.g. Murawski et al., 2000; Sale et al., 2005) but this is still subject of much debate. According to Krueck et al. (2017) conservation targets between $20 \%$ and $30 \%$ are a safer generic target than $10 \%$, both for biodiversity conservation and fisheries objectives, especially when considering largely unassessed ecosystems. Ideally, target protection values should be reviewed for each species/habitat based on relevant data, especially when they are the target of MPAs protection (Abecasis et al., 2015c). Therefore, rather than trying to find an optimal target, we chose to analyze three conservation targets $-10 \%, 30 \%$ and $50 \%$ protection - that represent the broad range of targets suggested in the MPA lierature (e.g. Murawski et al., 2000; Airame et al., 2003; Fraschetti et al., 2009; Krueck et al., 2017) and allow comparisons between them.

Third, our results illustrate the advantages of using MinPatch to improve the solutions provided by Marxan, as demonstrated by Smith et al. (2010). MinPatch adjusts the 
outputs from Marxan ensuring that all previewed protected areas are above a certain minimum size threshold. In fact, despite using the fine-tuning of the BLM, as suggested by Game and Grantham (2008), our results obtained by Marxan consisted in numerous, small protected areas. These solutions would be hard to implement due to difficulties in establishing and enforcing boundaries that can be easily recognized by the stakeholders, and to the higher monitoring and implementation costs, among others (Smith et al., 2010; Ban et al., 2011; McCrea-Strub et al., 2011). Importantly, such small MPAs would be less viable in providing true protection for marine species given the small amounts of protected habitat. MinPatch also has the added advantage of only increasing the size of smaller protected areas that are below the set threshold, unlike Marxan and other related software. In fact, the more common option of increasing the Marxan BLM to reduce patchiness in final scenarios will result in an increase in individual MPA size, even in the case of already large MPAs. This should result in suboptimal MPAs since these larger protected areas contain, in most cases, areas not needed to achieve the desired protection level and conservation target.

Importantly, the minimum size threshold should have an ecological meaning rather than being an ad-hoc choice. In our case, we selected a threshold $\left(5 \mathrm{~km}^{2}\right)$ that was considered to provide effective protection for the mobile benthic and benthopelagic fish assemblage. This was achieved by choosing a value that would represent at least twice the maximum individual home range area (and in most cases over 10 times) of the adults (i.e., the spawning biomass) of key fish species for Portuguese coastal waters based on the literature (Green et al., 2015). We acknowledge that this type of information is absent in most situations, but using proxies from studies in related species and areas is becoming more and more possible. This value is also within the interval $(4-6 \mathrm{~km})$ suggested to contain most larvae of short-distance dispersers, thus ensuring some degree of self-recruitment (Shanks et al., 2003).

Finally, the optimal distance between MPAs indicated in the literature may vary as much as $10-150 \mathrm{~km}$ (Palumbi, 2003; Shanks et al., 2003; Di Franco et al., 2015). Our MinPatch solutions are closer to the lower limits, suggesting that connectivity between MPAs is assured for most species in the final scenarios. Consequently, the MinPatch designs should not only provide enough protection to most larvae of short-distance dispersers and adults of key fish species, but also ensure connectivity to a wide range of species. However, it must be emphasized that in general there is still little information available regarding species dispersal and connectivity despite the fact that these represent factors of utmost importance for a MPA network.

\section{Conclusions}

Of the existing MPAs in the Portuguese coastal areas only one is below the minimum ecological size threshold considered. However, it must be taken in consideration that only a very small portion of the implemented MPAs offer de facto true protection, as only $1 \%$ of the existing MPAs are no-take. In addition, the current average distance between MPAs is larger than the optimal distance suggested by Shanks et al. (2003).
Our results demonstrate that even a small increase in the area under protection (from $479 \mathrm{~km}^{2}$ to $509 \mathrm{~km}^{2}$ ) and twice as much MPAs (from 6 to 11 MPAs) would provide effective protection to at least $10 \%$ of all coastal habitats while increasing the connectivity between them (from $80 \mathrm{~km}$ to $50 \mathrm{~km}$ average distance). Future research should strive to include other relevant data such as the distribution of key species (Abecasis et al., 2015c) and socio-economic data (e.g. fishing effort distribution, offshore aquaculture facilities and other human uses) (Klein et al., 2008; Ban et al., 2009; Smith et al., 2009).

Preliminary studies on the design of ecologically coherent and representative MPA networks have been carried out (e.g. Jones and Carpenter, 2009) but, overall, more information is needed in order to achieve truly coherent and fully functional MPA networks throughout the EU waters (Olsen et al., 2013). The development of solutions that include different protection levels should also be investigated.

Acknowledgment. DA acknowledges financial support from Fundação para a Ciência e Tecnologia (FCT) through a postdoc fellowship (SFRH/BPD/95334/2013).

\section{References}

Abecasis D, Erzini K. 2008. Site fidelity and movements of gilthead sea bream (Sparus aurata) in a coastal lagoon (Ria Formosa, Portugal). Estuar Coast Shelf Sci 79 (4): 758-763.

Abecasis D, Bentes L, Erzini K. 2012. Movements of Sarpa salpa (Linnaeus, 1758) (Sparidae) in a coastal lagoon (Ria Formosa, Portugal). J Appl Ichthyol 28 (1): 126-129.

Abecasis D, Afonso P, Erzini K. 2014. Can small MPAs protect local populations of a coastal flatfish, Solea senegalensis? Fish Manag Ecol 21 (3): 175-185.

Abecasis D, Horta e Costa B, Afonso P, Gonçalves E, Erzini K. 2015a. Early reserve effects linked to small home ranges of a commercial fish, Diplodus sargus, Sparidae. Mar Ecol Prog Ser 518: 255-266.

Abecasis D, Afonso P, Erzini K. 2015b. Changes in movements of white seabream (Diplodus sargus) during the reproductive season. Estuar Coast Shelf Sci 167: 499-503.

Abecasis D, Afonso P, Erzini K. 2015c. Toward adaptive management of coastal MPAs: the influence of different conservation targets and costs on the design of no-take areas. Ecol Inform 30: 263-270.

Afonso P, Abecasis D, Santos RS, Fontes J. 2016. Contrasting movements and residency of two serranids in a small Macaronesian MPA. Fish Res 177: 59-70.

Agardy T, Bridgewater P, Crosby MP, et al. 2003. Dangerous targets? Unresolved issues and ideological clashes around marine protected areas. Aquat Conserv Mar Freshw Ecosyst 13 (4): 353-367.

Agardy T, di Sciara GN, Christie P. 2011. Mind the gap: addressing the shortcomings of marine protected areas through large scale marine spatial planning. Mar Policy 35 (2): 226-232.

Airame S, Dugan JE, Lafferty KD, Leslie H, McArdle DA, Warner RR. 2003. Applying ecological criteria to marine reserve design: a case study from the California Channel Islands. Ecol Appl 13 (1): 170-184.

Ball IR, Possingham HP, Watts M. 2009. Marxan and relatives: software for spatial conservation prioritisation. In Moilanen A, Wilson KA, Possingham HP, eds. Spatial conservation 
prioritisation: quantitative methods and computational tools. Oxford, UK: Oxford University Press, pp. 185-195.

Ban NC, Hansen GJA, Jones M, Vincent ACJ. 2009. Systematic marine conservation planning in data-poor regions: socioeconomic data is essential. Mar Policy 33 (5): 794-800.

Ban NC, Adams V, Pressey RL, Hicks J. 2011. Promise and problems for estimating management costs of marine protected areas. Conserv Lett 4 (3): 241-252.

Boavida J, Paulo D, Aurelle D, et al. 2016. A well-kept treasure at depth: precious red coral rediscovered in Atlantic deep coral gardens (SW Portugal) after 300 years. PLOS ONE 11 (1): e0147228.

Bulleri F, Chapman MG. 2010. The introduction of coastal infrastructure as a driver of change in marine environments. J Appl Ecol 47 (1): 26-35.

Cunha AH, Assis JF, Serrão EA. 2013. Seagrasses in Portugal: a most endangered marine habitat. Aquat Bot 104: 193-203.

Di Franco A, Gillanders BM, De Benedetto G, Pennetta A, De Leo GA, Guidetti P. 2012. Dispersal patterns of coastal fish: implications for designing networks of marine protected areas. PLoS ONE 7 (2): e31681.

Di Franco A, Calò A, Pennetta A, De Benedetto G, Planes S, Guidetti P. 2015. Dispersal of larval and juvenile seabream: implications for Mediterranean marine protected areas. Biol Conserv 192: 361-368.

Di Lorenzo M, Claudet J, Guidetti P. 2016. Spillover from marine protected areas to adjacent fisheries has an ecological and a fishery component. J Nat Conserv 32: 62-66.

Fraschetti S, Ambrosio P, Micheli F, Pizzolante F, Bussotti S, Terlizzi A. 2009. Design of marine protected areas in a human-dominated seascape. Mar Ecol Prog Ser 375: 13-24.

Gaines SD, White C, Carr MH, Palumbi SR. 2010. Designing marine reserve networks for both conservation and fisheries management. Proc Natl Acad Sci USA 107 (43): 18286-18293.

Game ET, Grantham HS. 2008. Marxan user manual: for Marxan version 1.8.10. St. Lucia, Queensland, Australia/Vancouver, British Columbia, Canada: University of Queensland/Pacific Marine Analysis and Research Association.

Gray J. 1997. Marine biodiversity: patterns, threats and conservation needs. Biodivers Conserv 6 (1): 153-175.

Green AL, Maypa AP, Almany GR, et al. 2015. Larval dispersal and movement patterns of coral reef fishes, and implications for marine reserve network design. Biol Rev 90 (4): 1215-1247.

Guénette S, Lauck T, Clark C. 1998. Marine reserves: from Beverton and Holt to the present. Rev Fish Biol Fish 8 (3): 251-272.

Hall CM. 2001. Trends in ocean and coastal tourism: the end of the last frontier? Ocean Coast Manag 44 (9-10): 601-618.

Horta e Costa B, Gonçalves L, Gonçalves EJ. 2013. Vessels' site fidelity and spatio-temporal distribution of artisanal fisheries before the implementation of a temperate multiple-use marine protected area. Fish Res 148: 27-37.

Jackson JBC, Kirby MX, Berger WH, et al. 2001. Historical overfishing and the recent collapse of coastal ecosystems. Science 293 (5530): 629-637.

Jones PS. 2001. Marine protected area strategies: issues, divergences and the search for middle ground. Rev Fish Biol Fish 11 (3): 197216.

Jones PJS, Carpenter A. 2009. Crossing the divide: the challenges of designing an ecologically coherent and representative network of MPAs for the UK. Mar Policy 33 (5): 737-743.

Kaiser MJ. 2011. Uncertainty demands an adaptive management approach to the use of marine protected areas as management toolsworld fisheries: a social-ecological analysis. Wiley-Blackwell, pp. 351-358.

Klein CJ, Steinback C, Scholz AJ, Possingham HP. 2008. Effectiveness of marine reserve networks in representing biodiversity and minimizing impact to fishermen: a comparison of two approaches used in California. Conserv Lett 1: 44-51.

Krueck NC, Ahmadia GN, Possingham HP, Riginos C, Treml EA, Mumby PJ. 2017. Marine reserve targets to sustain and rebuild unregulated fisheries. PLOS Biol 15 (1): e2000537.

Lubchenco J, Palumbi SR, Gaines SD, Andelman S. 2003. Plugging a hole in the ocean: the emerging science of marine reserves. Ecol Appl 13 (1): S3-S7.

Magris RA, Pressey RL, Weeks R, Ban NC. 2014. Integrating connectivity and climate change into marine conservation planning. Biol Conserv 170: 207-221.

Margules CR, Pressey RL. 2000. Systematic conservation planning. Nature 405 (6783): 243-253.

McCay BJ, Jones PJS. 2011. Marine protected areas and the governance of marine ecosystems and fisheries. Conserv Biol 25 (6): 1130-1133.

McCrea-Strub A, Zeller D, Rashid Sumaila U, Nelson J, Balmford A, Pauly D. 2011. Understanding the cost of establishing marine protected areas. Mar Policy 35 (1): 1-9.

Metcalfe K, Vaughan G, Vaz S, Smith RJ. 2015. Spatial, socioeconomic, and ecological implications of incorporating minimum size constraints in marine protected area network design. Conserv Biol 29 (6): 1615-1625.

Mills M, Weeks R, Pressey RL, et al. 2015. Real-world progress in overcoming the challenges of adaptive spatial planning in marine protected areas. Biol Conserv 181: 54-63.

Molnar JL, Gamboa RL, Revenga C, Spalding MD. 2008. Assessing the global threat of invasive species to marine biodiversity. Front Ecol Environ 6 (9): 485-492.

Murawski SA, Brown R, Lai HL, Rago PJ, Hendrickson L. 2000. Large-scale closed areas as a fishery-management tool in temperate marine systems: the Georges Bank experience. Bull Mar Sci 66 (3): 775-798.

Olsen EM, Johnson D, Weaver P, et al. 2013. Achieving ecologically coherent MPA networks in Europe: science needs and priorities. In Larkin KE, McDonough N, eds. Marine board position paper 18. Ostend, Belgium: European Marine Board.

Palumbi SR. 2003. Population genetics, demographic connectivity, and the design of marine reserves. Ecol Appl 13 (spl): $146-158$.

Pauly D, Watson R, Alder J. 2005. Global trends in world fisheries: impacts on marine ecosystems and food security. Philos Trans $R$ Soc Lond B 360 (1453): 5-12.

Peña V, Bárbara I, Grall J, Maggs CA, Hall-Spencer JM. 2014. The diversity of seaweeds on maerl in the NE Atlantic. Mar Biodivers 44 (4): 533-551.

Roberts CM, Polunin NVC. 1991. Are marine reserves effective in management of reef fisheries? Rev Fish Biol Fish 1 (1): 65-91.

Sale PF, Cowen RK, Danilowicz BS, et al. 2005. Critical science gaps impede use of no-take fishery reserves. Trends Ecol Evol 20 (2): 74-80.

Shahidul Islam M, Tanaka M. 2004. Impacts of pollution on coastal and marine ecosystems including coastal and marine fisheries and approach for management: a review and synthesis. Mar Pollut Bull 48 (7-8): 624-649. 
Shanks AL, Grantham BA, Carr MH. 2003. Propagule dispersal distance and the size and spacing of marine reserves. Ecol Appl 13 (1): S159-S169.

Short FT, Wyllie-Echeverria S. 1996. Natural and human-induced disturbance of seagrasses. Environ Conserv 23 (1): 17-27.

Smith RJ, Eastwood YO, Rogers SI. 2009. Developing best practice for using Marxan to locate marine protected areas in European waters. ICES J Mar Sci 66: 188-194.
Smith RJ, Minin ED, Linke S, Segan DB, Possingham HP. 2010. An approach for ensuring minimum protected area size in systematic conservation planning. Biol Conserv 143 (11): 2525-2531.

Veiga P, Ribeiro J, Gonçalves JMS, Erzini K. 2010. Quantifying recreational shore angling catch and harvest in southern Portugal (north-east Atlantic Ocean): implications for conservation and integrated fisheries management. J Fish Biol 76 (9): $2216-2237$

Cite this article as: Abecasis D, Afonso P, Erzini K. 2017. An ecological framework for the development of a national MPA network. Aquat. Living Resour. 30: 14 